\title{
PENGARUH PELATIHAN DAN MOTIVASI KERJA TERHADAP KINERJA KARYAWAN
}

\author{
Friska Susanti Butar Butar ${ }^{1)}$, Irsutami, S.E., M.Acc., Ak ${ }^{2)}$ \\ Jurusan Manajemen Bisnis, Politeknik Neheri Batam \\ Jl. Ahmad Yani, Batam Centre, Batam 29461, Indonesia \\ 1) E-mail: friska.dfree@yahoo.co.id \\ ${ }^{2)}$ E-mail: irsutami@ polibatam.ac.id
}

\begin{abstract}
Abstrak
Tujuan penelitian ini adalah untuk mengetahui pengaruh pelatihan dan motivasi kerja terhadap kinerja karyawan. Pelatihan diukur dengan dimensi keterampilan dan pengetahuan, sedangkan motivasi kerja diukur dengan dimensi motif, harapan, dan insentif. Sementara itu kinerja karyawan dapat di ukur dengan indikator kuantitas hasil kerja, kualitas hasil kerja, kerja sama, pemahaman terhadap tugas, inisiatif, disiplin dan kehandalan. Responden dalam penelitian ini adalah 200 karyawan staf accounting yang bekerja pada perusahaan manufaktur di Batam, teknik analisa yang digunakan adalah analisis regresi linear sederhana. Hasil penelitian ini menemukan bahwa pelatihan dan motivasi kerja memiliki pengaruh positif terhadap kinerja karyawan. Berdasarkan hasil penelitian ini disarankan bagi pihak perusahaan untuk memberikan pelatihan yang memadai dan meningkatkan motivasi kerja karyawan guna meningkatkan produktivitas perusahaan. Penelitian ini hanya terbatas pada karyawan staf accounting di perusahaan manufaktur di Batam, maka penelitian selanjutnya disarankan untuk menggunakan sampel yang berbeda dan dari jenis perusahaan lainnya.
\end{abstract}

\section{Kata Kunci: pelatihan, motivasi kerja, kinerja karyawan.}

\begin{abstract}
The purpose of this study is to determine the effect of training and work motivation on employee performance. Training measured by the dimensions of skills and knowledge, while working motivation dimension is measured by motives, expectations, and incentives, and the employee's performance can be measured by indicators of quantity of work, quality of work, cooperation, understanding of the task, initiative, discipline and reliability. Respondents in this study were 200 employees of accounting staf who work in manufacturing companies in Batam, technique which is used to analyze this study is simple linear regression analysis. Results of the study found that training and motivation work have positive influence on employee performance. Based on these results it's advisable for the company to provide adequate training and increase employee motivation to improve the productivity of the company. This study is confined to the accounting staf employees in manufacturing companies in Batam, so further research is recommended to use the different samples and from other types of companies.
\end{abstract}

Keywords: Training, Motivation, Employee Performance. 


\section{Pendahuluan}

Manajemen kinerja karyawan adalah proses yang digunakan organisasi untuk memastikan bahwa karyawan memberikan kontribusi dalam menghasilkan produk atau jasa yang berkualitas bagi organisasi. Manajemen kinerja karyawan mendorong setiap karyawan untuk terlibat dalam perencanaan perusahaan.

[25] Mengatakan bahwa jika organisasi ingin bertahan dan berkembang, maka organisasi harus mencapai tujuan-tujuannya. Memproduksi barang dan jasa memenuhi permintaan pasar melibatkan usaha bersama dari banyak orang. Usaha bersama ini harus dikoordinasikan dan dikelola pada banyak tingkatan yang berbeda, yaitu di dalam organisasi, antar organisasi, pada tingkatan nasional dan internasional. Dari penjelasan tersebut dapat disimpulkan bahwa sebuah organisasi dapat bertahan jika organisasi tersebut memiliki karyawan yang mampu memberikan kontribusi optimal, maka organisasi akan berkembang dengan baik sehingga mendapatkan kinerja yang baik dalam mencapai tujuan organisasi.

Tujuan organisasi akan tercapai jika karyawan melakukan tugasnya dengan tepat dan sebaik-baiknya, sehingga dalam upaya meningkatkan kinerja karyawan perusahaan harus mengusahakan sumber daya manusia yang berkualitas. Schermerhorn menyatakan bahwa organisasi merupakan sistem terbuka yang berinteraksi dengan lingkungannya dalam proses yang berkelanjutan dari transformasi masukan sumber daya menjadi keluaran produk jadi dan jasa [15].

[21] membagi aktivitas manajemen Sumber Daya Manusia (SDM) menjadi tujuh bagian, yaitu: perencanaan sumber saya manusia; rekrutmen; seleksi; sosialisasi; pelatihan dan pengembangan; penilaian prestasi kerja, dan promosi. Penelitian ini difokuskan pada kegiatan pelatihan yang diadakan organisasi untuk karyawannya sebagai upaya mendapatkan hasil yang optimal bagi organisasi.

[21] Mengatakan bahwa program pelatihan adalah proses yang didesain untuk mempertahankan atau memperbaiki prestasi kerja saat ini, sedangkan pengembangan adalah proses mendesain untuk pengembangan keterampilan yang perlu dilakukan untuk aktivitas pekerjaan di masa depan.

Pelatihan sangat dibutuhkan untuk meningkatkan kinerja karyawan, sehingga dengan adanya pelatihan, karyawan akan menyadari apa saja spesifikasi perkerjaan mereka dan keterampilan apa saja yang mereka miliki. Tingkat motivasi karyawan akan meningkat juga memberi manfaat dalam menghasilkan kinerja makasimal yang akan membantu perusahaan dalam mencapai tujuan organisasi secara efektif. Pelatihan adalah proses pembelajaran yang melibatkan akuisisi pengetahuan, mengasah keterampilan, konsep, aturan, atau mengubah sikap dan perilaku untuk meningkatkan kinerja karyawan [8].

[14] Menyatakan bahwa kinerja laki-laki dan perempuan sama-sama memberikan kontribusi terhadap pencapaian tujuan. Laki-laki dan perempuan sama-sama bertanggung jawab dan memiliki kepentingan yang sama dalam organisasi.

Motivasi karyawan akan meningkat ketika organisasi mampu memberdayakan karyawannya sehingga karyawan dapat menjalankan pekerjaannya dengan baik. Secara psikologis karyawan akan memiliki motivasi ketika karyawan mengetahui tujuan dan arah perkerjaannya [9].

Motivasi dapat diartikan sebagai dorongan spiritual yang seseorang berikan terhadap orang lain untuk melakukan sebuah pekerjaan ataupun menghasilkan suatu produk. Motivasi merupakan proses yang menjelaskan intesitas, arah, dan ketekunan seorang individu untuk mencapai tujuannya [17].

Bagi perusahaan, sangat penting untuk mengetahui tingkat motivasi kerja karyawannya, agar kinerja karyawan selalu optimal dan produktivitas karyawanpun meningkat. Pemberian pelatihan kepada karyawan juga dapat menambah kemampuan dan pengetahuan karyawan sehingga kinerja karyawan meningkat guna mencapai tujuan dari perusahaan dan mampu bersaing dalam dunia bisnis. Penelitian sebelumnya yang dilakukan oleh [8] menyatakan bahwa pelatihan dan motivasi kerja 
berpengaruh positif terhadap kinerja karyawan. Berdasarkan penjelasan tersebut, maka peneliti tertarik untuk melakukan penelitian yang berjudul:

"PENGARUH PELATIHAN DAN MOTIVASI KERJA TERHADAP KINERJA KARYAWAN".

\section{Landasan Teori}

\subsection{Pelatihan}

Pelatihan sangat diperlukan untuk pengembangan bagi sumber daya manusia agar para karyawan bisa paham dan mengerti atas pekerjaan mereka sehingga apa yang menjadi tujuan perusahaan bisa dengan cepat terlaksana dan mencapai target yang diharapkan [24].

[21] Mengatakan bahwa program pelatihan adalah proses yang didesain untuk mempertahankan atau memperbaiki prestasi kerja saat ini, sedangkan pengembangan adalah proses mendesain untuk pengembangan keterampilan yang perlu dilakukan untuk aktivitas pekerjaan di masa depan.

\subsection{Motivasi Kerja}

Di dalam konsep manajemen kata motivasi didefenisikan sebagai semua upaya untuk memunculkan dari dalam semangat orang lain (bawahan) agar mau bekerja keras guna mencapai tujuan organisasi melalui pemberian atau penyediaan pemuasan kebutuhan mereka [20].

David McCelland [21] menyatakan bahwa ada tiga macam dorongan mendasar dalam diri orang yang termotivasi, yaitu: (a) Kebutuhan untuk berprestasi (need for achievement, (b) Kebutuhan berafiliasi (need for affiliation), dan (c) Kebutuhan kekuatan (need for power).

\subsection{Kinerja Karyawan}

[16] Menyatakan bahwa kinerja adalah suatu fungsi dari motivasi dan kemampuan untuk menyelesaikan tugas atau pekerjaan, seseorang harus memiliki derajat kesediaan dan tingkat kemampuan tertentu. Menurut [27] kinerja dipengaruhi oleh faktor individual yang terdiri dari kemampuan atau keahlian, faktor psikologis yang terdiri dari persepsi, attitude (sikap), pembelajaran, dan motivasi, dan faktor organisasi yang terdiri dari sumber daya, kepemimpinan, penghargaan, struktur dan job design.

\subsection{Hipotesis}

[18] Menyatakan bahwa pelatihan karyawan adalah kegiatan manajemen SDM yang penting untuk dilakukan, karena ketika tuntutan pekerjaan berubah, maka keahlian karyawan harus diubah dan diperbaharui. [11] menyatakan bahwa keterampilan dan pengetahuan karyawan dapat ditingkatkan melalui pelatihan. Keterampilan dan pengetahuan karyawan yang baik dapat meningkatkan motivasi kerja karyawan dan berujung pada meningkatnya kinerja karyawan.

[1] Menemukan bahwa pelatihan berpengaruh positif terhadap kinerja karyawan. [22] Menemukan bahwa pelatihan memiliki pengaruh yang signifikan terhadap kinerja karyawan. [19] Menemukan bahwa pelatihan berpengaruh positif terhadap kinerja karyawan.

H1: Pelatihan berpengaruh positif dan signifikan terhadap kinerja karyawan.

[12] Menjelaskan bahwa karyawan akan termotivasi untuk berusaha dengan baik dan percaya bahwa jika pekerjaan yang baik akan membawa penilaian yang baik terhadap kinerja mereka, yang pada nantinya akan diikuti oleh penghargaan dari organisasi, baik secara material sebagai bonus, meningkatkan, atau promosi, atau immaterially sebagai pujian dan pengakuan.

[13] Menyatakan bahwa motivasi kerja berpengaruh positif terhadap kinerja karyawan. Penelitian [10] pada pegawai kantor PDAM Kota Surakarta menyatakan bahwa motivasi berpengaruh pengaruh positif dan signifikan terhadap kinerja. Berdasarkan hubungan antar variabel yang telah diuraikan di atas, maka diajukan:

H2: Motivasi kerja berpengaruh positif dan signifikan terhadap kinerja karyawan. 


\section{Hasil Dan Pembahasan}

3.1 Instrumen Penelitian dan Operasional Variabel Penelitian ini mengumpulkan dan mengolah data primer yang diperoleh dari kuesioner yang meliputi variabel pelatihan, motivasi dan kinerja karyawan pada responden dengan memberi bobot penilaian pada setiap pernyataan kuisioner. Sebelum kuesioner didistribusikan kepada responden, kuesioner tersebut akan terlebih dahulu diuji validitas dan reliabilitasnya.

Jenis data yang akan dikumpulkan adalah data ordinal. Instrumen pertanyaan menggunakan skala Likert 5 poin, yaitu: sangat setuju, setuju, kurang setuju, tidak setuju dan sangat tidak setuju untuk setiap jawaban responden dari masing-masing pernyataan penelitian. Untuk pembobotan pernyataan, penilaiannya adalah: (1) jawaban sangat setuju bernilai 5; (2) jawaban setuju bernilai 4; (3) jawaban cukup setuju bernilai 3; (4) jawaban tidak setuju bernilai 2; dan (5) jawaban sangat tidak setuju bernilai 1 .

\subsection{Populasi, Sampel dan Teknik Penarikan Sampel}

Populasi dari penelitian ini adalah perusahaan manufaktur yang ada di Batam. Obyek penelitian dari penelitian ini adalah staf accounting dari masingmasing perusahaan, dimana peneliti mengambil satu sampel dari masing-masing perusahaan sebagai perwakilan. Jumlah perusahaan manufaktur yang beroprasi di Batam adalah 289 perusahaan, sehingga jumlah objek dari penelitiaan ini adalah 289 staf accounting. Teknik Penetapan jumlah sampel yang digunakan adalah purposive sampling. Sampel di dalam penelitian ini menggunakan rumus slovin, yaitu 168 staf accounting.

\subsection{Validitas dan Reliabilitas Instrumen}

[5] Butir pernyataan kuesioner dinyatakan valid jika nilai rhitung > rtabel. Dengan rtabel $=0,361$ maka semua butir pernyataan yang digunakan dinyatakan valid karena memiliki nilai rhitung> rtabel.
Tabel 1. Uji Reliabilitas

\begin{tabular}{ll}
\hline Variabel & $\begin{array}{l}\text { alpha- } \\
\text { Cronbach }\end{array}$ \\
\hline Pelatihan & 0.764 \\
Motivasi Kerja & 0.816 \\
Kinerja Karyawan & 0.716 \\
\hline
\end{tabular}

Butir pernyataan kuesioner dalam penelitian ini dinyatakan reliabel karena nilai alpha-Cronbach masing-masing variabel penelitian, yang ditunjukkan pada tabel 1, lebih besar dari 0,60 .

\subsection{Analisis Data}

Data dianalisis dengan menggunakan SPSS versi 20.0. Analisis regresi sederhana digunakan untuk menganalisis bagaimana pengaruh insentif moneter, insentif non-moneter, kemauan karyawan, kebanggaan karyawan dan kesetiaan karyawan terhadap prestasi kerja. Model persamaan regresi dinyatakan sebagai berikut: $\mathrm{KK}=\mathrm{a}+\mathrm{b} 1 \mathrm{IP}+\mathrm{e} \ldots$ (1)

$\mathrm{KK}=\mathrm{a}+\mathrm{b} 1 \mathrm{IMK}+\mathrm{e} \ldots$ (2)

Keterangan:

$\mathrm{KK}=$ Kinerja Karyawan

$$
\begin{array}{ll}
\mathrm{a} & =\text { konstanta } \\
\mathrm{b} 1 & =\text { koefisien regresi } \\
\mathrm{P} & =\text { Pelatihan } \\
\mathrm{MK}=\text { Motivasi Kerja } & \\
\mathrm{e} 1, \mathrm{e} 2 & =\text { residual }
\end{array}
$$

Tabel 2. Analisis Regresi Model 1

\begin{tabular}{llll}
\hline Variabel & $\begin{array}{l}\text { R } \\
\text { square }\end{array}$ & T & Sig. \\
\hline Pelatihan & 0.45 & 3.058 & 0.003 \\
\hline
\end{tabular}

Berdasarkan tabel 2 di atas, variabel insentif moneter memiliki nilai signifikansi lebih kecil dari 0.05, maka disimpulkan bahwa pelatihan berpengaruh positif terhadap kinerja karyawan, sehingga H1 terdukung. Pelatihan memiliki Adjusted R square sebesar 0,45. Hal ini berarti prestasi kerja karyawan dapat ditingkatkan sebesar $45 \%$ oleh variabel insentif moneter sedangkan sisanya $(100 \%-43 \%=57 \%)$ dijelaskan oleh variabel lain.

Hal ini juga dapat diartikan bahwa pelatihan yang 
diperoleh karyawan dari perusahaan membantu melaksanakan tugas pokok karyawan tersebut sesuai dengan fungsi dan masing-masing karyawan. Hasil uji hipotesis pada penelitian ini sesuai dengan penelitian [23] yang menunjukkan bahwa variabel pelatihan berpengaruh signifian terhadap kinerja karyawan. Hasil dari penelitian ini juga sesuai dengan penelitian dari [19] yang menyatakan bahwa pelatihan pada karyawan berpengaruh positif terhadap kinerja karyawan. [4] Menyatakan bahwa pelatihan dan imbalan dapat meningkatkan level kinerja seluruh anggota organisasi. Penelitian ini juga didukung oleh [3] yang menunjukkan bahwa pemberian pelatihan sangat diperlukan dan sangat penting terutama bagi dunia perindustrian.

Tabel 3. Analisis Regresi Model 2

\begin{tabular}{llll}
\hline Variabel & R & T & Sig. \\
& square & & \\
\hline Motivasi Kerja & 0.021 & 2.056 & 0.041 \\
\hline
\end{tabular}

Berdasarkan tabel 3 di atas, variabel motivasi kerja memiliki nilai signifikansi lebih kecil dari 0.05, maka disimpulkan bahwa motivasi kerja berpengaruh positif terhadap kinerja karyawan, sehingga $\mathrm{H} 2$ terdukung. Motivasi kerja memiliki Adjusted R square sebesar 0,021. Hal ini berarti prestasi kerja karyawan dapat ditingkatkan sebesar $2,1 \%$ oleh variabel insentif nonmoneter sedangkan sisanya $(100 \%-2,1 \%=97,9 \%)$ dijelaskan oleh variabel lain. Hasil penelitian ini sesuai dengan penelitian [7] yang menyatakan bahwa motivasi berpengaruh positif dan signifikan terhadap kinerja karyawan. Semakin baik perusahaan memotivasi karyawannya, maka semakin besar pula motivasi karyawan untuk mengerjakan tugasnya sehingga memberikan dampak yang positif bagi perusahaan dalam kinerja dan produktivitas serta memberikan efisiensi waktu dalam menyelesaikan target perusahaan. Hasil dari penelitian ini juga sesuai dengan penelitian [6] yang menyatakan bahwa motivasi kerja karyawan sangat mempengaruhi kinerja dari karyawan tersebut di dalam sebuah organisasi. Dalam penelitian tersebut juga diungkapkan bahwa motivasi kerja karyawan dapat terdorong tidak terlepas dari pemberian imbalan yang sesuai dan pemberian insentif yang memadai kepada karyawan. [2] Mengungkapkan bahwa motivasi mempunyai pengaruh yang sangat kuat terhadap kinerja karyawan dan juga memberikan dampak kepada kepuasan kerja karyawan tersebut. [26] Mengungkapakan bahwa tanpa motivasi, karyawan dalam sebuah organisasi tidak dapat menjalankan dan menempuh target yang telah perusahaan tentukan. Berdasarkan hasil penelitian tersebut, motivasi memiliki hasil yang positif dan sangat signifikan terhadap kinerja karyawan.

\section{Kesimpulan}

Berdasarkan hasil penelitian mengenai pelatihan, motivasi kerja, dan kinerja karyawan pada karyawan level menengah bagian accounting department yang ada di perusahaan manufaktur Batam, dapat ditarik kesimpulan yang sesuai dengan perumusan masalah sebagai berikut: (a) Pelatihan berpengaruh positif dan signifikan terhadap kinerja karyawan. Hal ini berarti pelatihan yang diterima oleh karyawan memiliki pengaruh terhadap kinerja karyawan. (b) Motivasi kerja berpengaruh positif dan signifikan terhadap kinerja karyawan. Hal ini berarti motivasi juga merupakan salah satu faktor yang memepengaruhi kinerja karyawan.

Penulis menemukan beberapa keterbatasan di dalam penelitian ini, yaitu sampel pada penelitian ini hanya terbatas pada karyawan staf accounting di perusahaan manufaktur di Batam, sehingga kemungkinan akan diperoleh hasil yang berbeda jika menggunakan sampel dari perusahaan lain atau bahkan di daerah lain.

Berdasarkan keterbatasan dan implikasi pada penelitian ini, penulis menyampaikan agar penelitian selanjutnya disarankan untuk menggunakan sampel dari jenis perusahaan lain atau tetap menggunakan jenis perusahaan yang sama, namun diterapkan di daerah lain, karena perbedaan budaya dan lingkungan di masing-masing daerah dapat mempengaruhi persepsi karyawan. Selain itu, dapat menggunakan sampel karyawan lain, tidak hanya 
terbatas pada karyawan yang bekerja pada bagian keuangan (accounting department) namun bisa menggunakan sampel dari bagian lain, atau karyawan secara umum.

\section{Daftar Referensi}

[1] Agusta, Leonando, \& Sutanto, E. M. (2012). Pengaruh Pelatihan Dan Motivasi Kerja Terhadap Kinerja Karyawan Cv Haragon Surabaya. Surabaya. e-Jurnal. Vol. 1, No.3 http//fportfolio.petra.ac.id/user_fi.

[2] Ahmed, A. M., \& Muhamud, G. Y. (2015). The Impact Of Motivation On Public Personnel Job Performance In Bandir Regional Administration Of Somali Federal Goverment. Academic Research Journal Vol. 6(2) ISSN-2223-9944, 138-146.

[3] Denby, S. (2010). The Importance of Training Need Analysis, Industry and Commercial Training. Emerald Group Publishers Vol. 43 No. 3, 147-150.

[4] Farooq, M. (2011). Impact of Training and Feedback on Employee Performance. Far East Journal of Psychology and Business Vol 5 No. 1, 23-33.

[5] Ghozali, I. (2012). Aplikasi Analisis Multivariate Dengan Program SPSS. Semarang: BP Universitas Diponegoro.

[6] Joselyne, M. (2014). The Impact Of Employee Motivation On Overall OrganisationalL Performance. Dipetik Agustus 27, 2015, dari https://www.academia.edu: https://www.academia.edu/6995422/THE_IMP ACT_OF_MOTIVATION_ON_WORKERS_P ERFORMANCE_A_CASE_STUDY_OF_IGA RA_GROWERS_TEA_FACTORY

[7] Kalesaran, F. H., Mandey, S. L., \& Mekel, P. A. (2014). Pengaruh Motivasi, Penempatan Kerja, Dan Pengembangan Karir Terhadap Kinerja Pegawai Pada Badan Lingkungan Hidup Provinsi Sulawesi Utara. EMBA ISSN 23031174 Vol. 2 No. 4, 184-194.
[8] Khan, M. I. (2012). The Impact of Training and Motivation on Performance of Employee. Business Review - Volume 7 Number 2.

[9] Kreitner, R. (1995). Management, 6th ed. Boston: Houghton Mifflin Company.

[10] Listianto, T., \& Setiaji, B. (2007). Pengaruh Motivasi Kepuasan dan Disiplin Kerja Terhadap Kinerja Karyawan (Studi Kasus Di Lingkungan Pegawai Kantor PDAM Kota Surakarta. http://www.damandiri.or.id.

[11] Lubis, K. A. (2014, May 30). Pengaruh Pelatihan dan Motivasi Kerja Terhadap Kinerja Karyawan PT. Perkebunan Nusantara IV (Persero) Medan. Diambil kembali dari repository.usu.ac.id: http://repository.usu.ac.id/bitstream/123456789 14316/1/09E01349.pdf

[12] Luthans, F. (2006). Perilaku Organisasi. Yogyakarta: ANDI.

[13] Ma'rifah, D. (2006). Pengaruh Motivasi Kerja dan Budaya Organisasi Terhadap Kinerja Pekerja Sosial pada Unit Pelaksana Teknis Dinas Sosial Propinsi Jawa Timur. http://www.damandiri.or.id..

[14] Malik, M. E. (2011). Organizational Effectiveness: A Case Study of Telecommunicaton and Banking Sector of Pakistan. Far East Journal of Psychology and Business, Vol. 2 No. 1.

[15] Puspopranoto, S. (2001). Manajemen Bisnis; Konsep dan Aplikasi. Jakarta: PPM.

[16] Rivai, V. (2005). Manajemen Sumber Daya Manusia untuk Perusahaan. Dari Teori Ke Praktik. Jakarta: PT Raja Grafindo Persada.

[17] Robbin, S. P., \& Judge, T. A. (2008). Perilaku Organisasi. Jakarta: Salemba Empat..

[18] Robbin, S. P., \& Coulter, M. (2009). Manajemen, edisi kedelapan jilid 1. (H. Slamet, Penerj.) Jakarta: PT Indeks.

[19] Rori, W. J., Mekel, P. A., \& Ogi, I. (2014). Pendidikan Pelatihan dan Penempatan Kerja Pengaruhnya Terhadap Kinerja Karyawan Di Kantor Inspektoran Kota Mandado. EMBA ISSN 2303-1174, 1284-1295. 
[20] Siswandi. (2011). Aplikasi Manajemen Perusahaan: Analisis Kasus dan Pemecahannya. Jakarta: Mitra Wacana Media.

[21] Stoner, J. A., Freeman, R. E., \& Gilbert, D. R. (1996). Manajemen Jilid II. Jakarta: Bhuana Ilmu Populer.

[22] Sutono, \& Suroso, I. (2009). Pengaruh Reward Pelatiahan dan Lingkungan Kerja Yang Berdampak Pada Peningkatan Kinerja Pengelola BMT Bus Lasem. Analisis Manajemen ISSN 1411-199 Vol. 4 No. 1.

[23] Turere, V. N. (2013). Pengaruh Pendidikan Dan Pelatihan Terhadap Peningkatan Kinerja Karyawan Pada Balai Pelatihan Teknis Pertanian Kalasey Manado. EMBA ISSN 2303-1174 Vol. 1 No. 3, 10-19.

[24] Yani., S. M. (2012). Manajemen Sumber Daya Manusia. Jakarta: Mitra Wacana Media.

[25] Zakiyudin, A. (2013). Teori Dan Praktek Manajemen. Jakarta: Mitra Wacana Media.

[26] Zameer, H., Ali, S., Nisar, W., \& Amir, M. (2014). The Impact of the Motivation on the Employee's Performance in Beverage Industy Pakistan. International Journal of Academic Research in Accounting, Finance and Management Sciences Vol. 4 No. 1 E-ISSN: 2225-8329, 293-298.

[27] Mangkunegara, A. P. (2005). Evaluasi Kinerja Sumber Daya Manusia. Cetakan I. Bandung: PT Refika Aditama. 